\title{
Optimization of plow adjustment
}

\author{
Damir Khaliullin ${ }^{1 *}$, Alexandr Belinsky ${ }^{1}$, Ayrat Valiev $^{1}$, Ruslan Lukmanov ${ }^{1}$ and Gaston Bourges ${ }^{2}$ \\ ${ }^{1}$ Kazan State Agrarian University, Kazan, 420015, Russia \\ ${ }^{2}$ National University of Rosario (UNR - FCEIA), Rosario city, Argentina
}

\begin{abstract}
Optimization of plow adjustment is very important for national economy, especially in solving problems of increasing agricultural production and reducing energy consumption during plowing. One of the ways to optimize the plow adjustment is to reduce the friction forces of the plow from pressure on the bottom of the furrow and the walls of the furrow. To optimize the configuration of the plow, various methods and techniques are proposed and used that have certain advantages and disadvantages. One of the promising directions of reducing the friction forces of the plow is a dynamic method that uses adjustments of specific devices of the plow and tractor linkage mechanisms. However, one of the significant drawbacks of these adjustments is the shift of the tractor traction point from the longitudinal axis of symmetry of the tractor. The accepted working hypothesis and the studies of the process dynamics made it possible to determine the optimal parameters of the calculated and structural displacement of the tractor thrust point from the resistance line of the plow, as well as to develop recommendations for manufacturers of plows and agricultural tractors.
\end{abstract}

\section{Introduction}

Plowing is one of the main and energy-intensive technological operations in the cultivation of crops. Despite the widespread introduction of various energysaving technologies in agriculture around the world, which involve minimizing or completely abandoning soil cultivation, it is currently not possible to replace plowing with anything else [1-4]. This operation is an integral (mandatory) part in the cultivation of row crops, many industrial and other crops. It is also an effective agricultural technique in the fight against weeds, diseases, pests and is necessary when applying organic fertilizers (manure) for its incorporation into the soil, etc. [5].

According to various scientists, depending on the technology adopted, the type of cultivated crops, it accounts for up to $40 \%$ of all energy costs [6].

In this case, the correct setting of the arable unit is of particular importance since it has a significant impact on energy costs when performing a technological operation. It is known that the general pulling resistance of a plow consists of the necessary efforts to perform useful work - cutting, crumbling and wrapping the soil layer, and to overcome the friction forces of the hulls against the bottom and furrow walls - "useless" work. Efficiency coefficient of the plow shows which part of its resistance is spent on useful work - overcoming the living resistance of the soil, and which for useless movement along the field of the plow [7-9].

It is known that the optimum value of the function is the extremum: maximum or minimum. In our case, when setting up the plow: obtaining the highest value of the efficiency of the plow or the lowest value of traction resistance. These tasks are solved in various ways; let us consider in more detail some of the most common.

For a stable plow in the furrow, you must attach the plow to the tractor so that line $O_{1} O_{2}$ (Figure 1) of the traction force intersects track $\mathrm{O}_{2}$ of the gravity center of the plow and the hinge $H$ for attaching the lower longitudinal rods to the tractor [10]. The trace of the center of gravity of the plow is in the middle of a straight line connecting the socks of the first and last bodies.

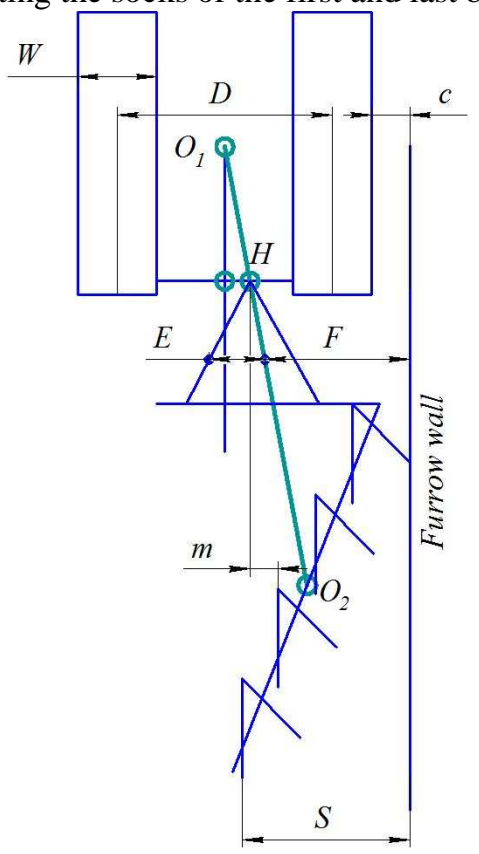

Fig. 1. The configuration scheme of the arable unit of Russian production

\footnotetext{
* Corresponding author: damirtag@mail.ru
} 
For the correct aggregation of mounted and semimounted plows, draw a straight line from point $O_{1}$ to point $O_{2}$ and find the necessary shift $E$ of the attachment on the tractor and the distance $F_{0}$ from the suspension axis of the plow to the furrow of the front body share. Installation dimensions $E$ and $F$ depend on the number of enclosures. Therefore, to aggregate plows PLN-5-35 and PLP-6-35 in four-, five- and six-body variants with $\mathrm{T}-150$ and $\mathrm{T}-150 \mathrm{~K}$ tractors, it is possible to install the plow suspension in four positions: the middle of the suspension is placed against the toe of the third case (displacement $m$ is equal to zero), the middle of the suspension is shifted to the left by 60,120 and $220 \mathrm{~mm}$.

An analysis of the circuit in Figure 1 shows that the tractor traction line is shifted to the left of the longitudinal line of the plow resistance. This leads to an increase in pressure on the walls of the furrows, an increase in the friction force and a decrease in the efficiency of the plow.

Lemken company offers its own option of setting up a plow for stable running in the furrow - the Optiquick system (Figure 2) [11]. The plow is considered optimally tuned if the tractor-plow traction line is the line between points $Z$ and $P Z$, passes through the middle of the rear axle of the tractor - point $M$. Point $Z$ is the point at which imaginary elongated lower links intersect, point $P Z$ is the middle of the plow frame (figure 2).

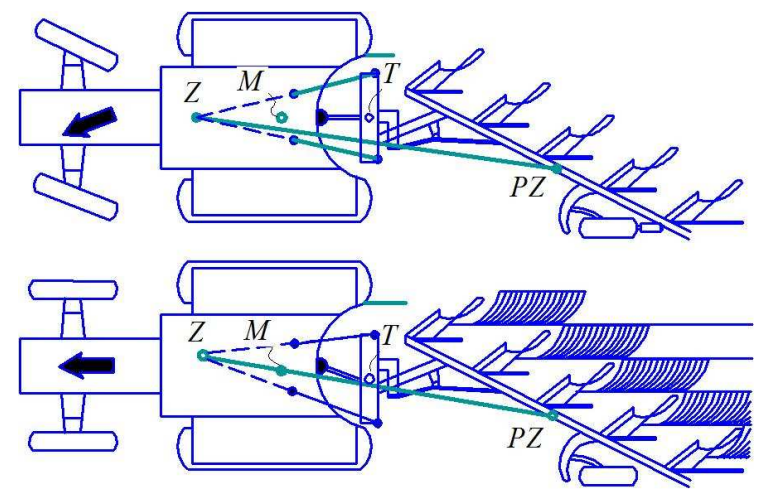

Fig. 2. Tillage configuration diagrams using the Optiquick system

Firstly, the width of the first housing is set. An external screw is used for this. The tractor-plow traction line in the upper figure 2 is still not ideal since the line between points $\mathrm{Z}$ and $\mathrm{PZ}$ does not pass through the middle of the rear axle. Then remove the lateral draft using the internal screw. Now the tractor-plow traction line intersects the rear axle of the tractor at point $\mathrm{M}$. At the same time, the adjustment of the lateral traction did not affect the width of the first furrow.

From the analysis of the circuits in Figure 2, we can make several observations:

1 st. Point $\mathrm{Z}$ is the point of the mass center of the tractor and the "pole" $\pi$ of the articulated four-link lower links - top view.

2nd. Point $\mathrm{Z}$ in the lower figure 2 is "shifted" to the right relative to the longitudinal axis of the tractor.

3rd Point $\mathrm{M}$ - point of tractor traction, which is indicated in the center of the tractor' drive wheels, and is not really a point of tractor traction. 4th. The point $\mathrm{T}-$ traction of the tractor in Figure 2 was added for clarity by the authors of this article. Without an indication of the actual point $\mathrm{T}$ of the tractor's thrust, the analysis of the stability of the plow's travel is difficult and leads to erroneous conclusions.

The aim of the study is to reduce the energy costs for plowing the soil by reducing the friction forces of the plow bodies from pressure on the bottom and the furrow walls, as well as optimizing the setting of the arable unit by determining the optimal location of the plow traction point in the longitudinally-vertical and horizontal planes.

\subsection{Working hypothesis}

The plow is optimally adjusted in the longitudinalvertical plane if the line of tractor pull, the center of mass point, the tractor and plow pull and the application of the plow drag force are on the same line and intersect at the $\pi$ pole - the point of the imaginary extended lower link of the tractor linkage mechanism.

To reduce the pressure of the field planks on the furrow wall and reduce the friction force, it is necessary to shift the plow thrust point in the horizontal plane from the longitudinal line of the plow resistance point by the optimal value e, which will allow balancing the moments of forces: tractor thrust $P_{x}$ and resistance $R_{x}$, as well as the moment of resistance $\mathrm{R}_{\mathrm{y}}$ plow.

\section{Materials and methods}

The main results of the work are obtained on the basis of theoretical studies using methods of mechanics, analytical geometry and the laws of agricultural mechanics. The analysis of technological process dynamics of various arable units was carried out taking into account the design parameters of the plow plows, the chassis and tractor linkage, as well as the physicomechanical properties of the treated soil.

\section{Results and Discussion}

Consider the adjustment of the plow in the longitudinally vertical plane (Figure 3).

The linkage mechanisms of the tractor and the plow must be adjusted so that the line of force $\boldsymbol{P}_{\boldsymbol{X} Z}$ of the tractor's thrust passes through the pole $A$ of the center of mass of the tractor - through point $B$ of the tractor's thrust - through point $C$ of the instantaneous center of force $\boldsymbol{R}_{X Z}$ of the plow's resistance (points A, B, C were on the same straight line).

This is ensured by adjusting the tractor linkage mechanism (central link, left and right link braces) and the linkage ("tower") of the plow so that the extension of the link line coincides with the $\pi$ pole of the articulated four-link linkage of the tractor linkage and with point $A$ of the tractor center of mass, as well as with point $C$ of the instantaneous center of resistance of the plow of force $\boldsymbol{R} \mathbf{x z}$.

The projection of the tractor pull force $\boldsymbol{P}_{\mathbf{X Z}}$ and the resistance of the plow $\boldsymbol{R} \mathbf{x z}$ are equal to each other, but opposite in direction and are on the same line drawn 
through the indicated points. It is known that to move a body along a plane with friction, a minimum tractor pull force $P$ will be required when it is directed horizontally at an angle $\varepsilon$ equal to or greater than the friction angle $\varphi$ [12]. The angle of friction of steel on the soil is in the range of $14 \ldots 42^{\circ}$, and its average value is $26^{\circ} 30^{\prime}$.

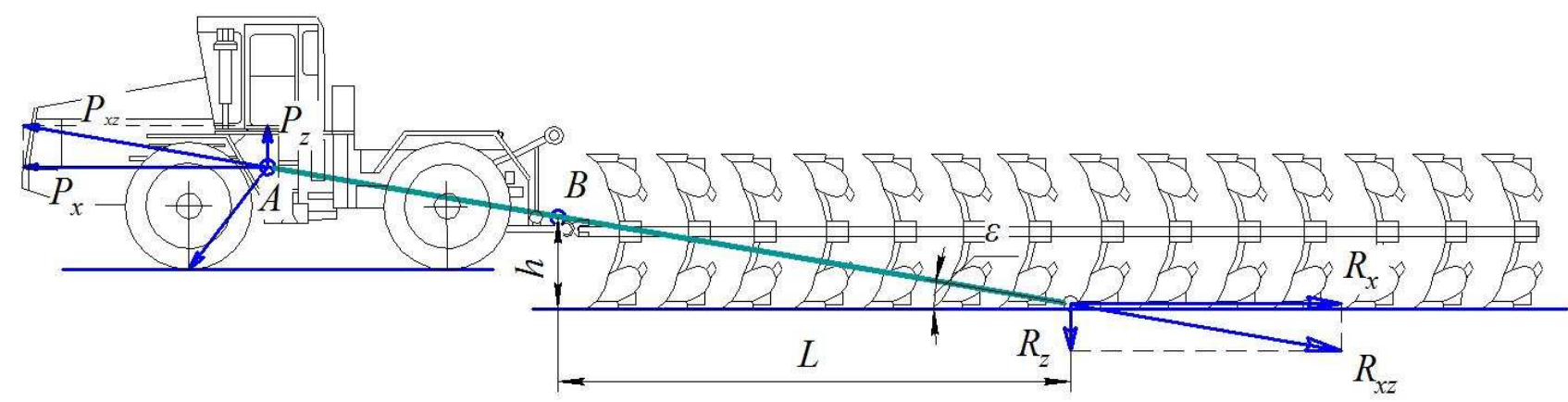

Fig. 3. Scheme of plow adjustment in a longitudinally vertical plane: A - mass center of the tractor; B - tractor traction point (point $\mathrm{B}$ - at the same time is the traction point of the plow linkage mechanism); $\mathrm{C}$ is the point of the instantaneous center of plow resistance; $\boldsymbol{P} \mathbf{x z}$ - tractor traction force; $\boldsymbol{P} \mathbf{x}$ is the projection of the tractor traction force on the OX axis; $\boldsymbol{P z}$ is the projection of tractor traction force on the $\mathrm{OZ}$ axis; $\boldsymbol{R} \mathbf{x z}$ is the projection of the tractor traction force on the $\mathrm{OZ}$ axis; $\boldsymbol{R} \mathbf{x}$ - projection of the resistance force of the plow on the axis OX; $\boldsymbol{R z}-$ projection of the plow resistance force on the axis OZ.

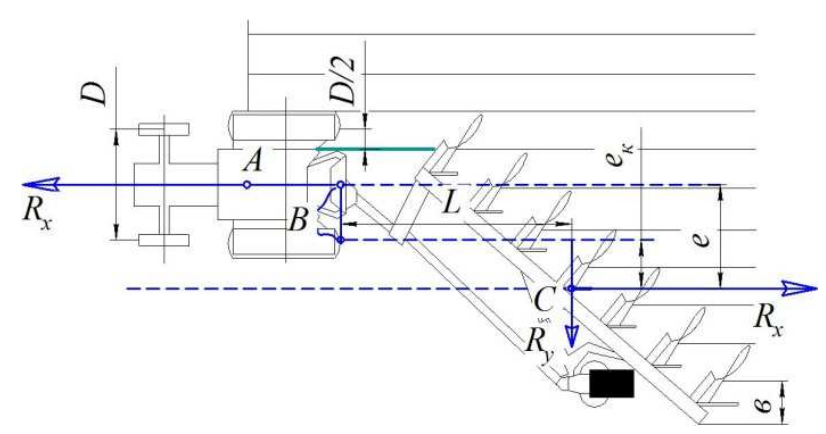

$a$

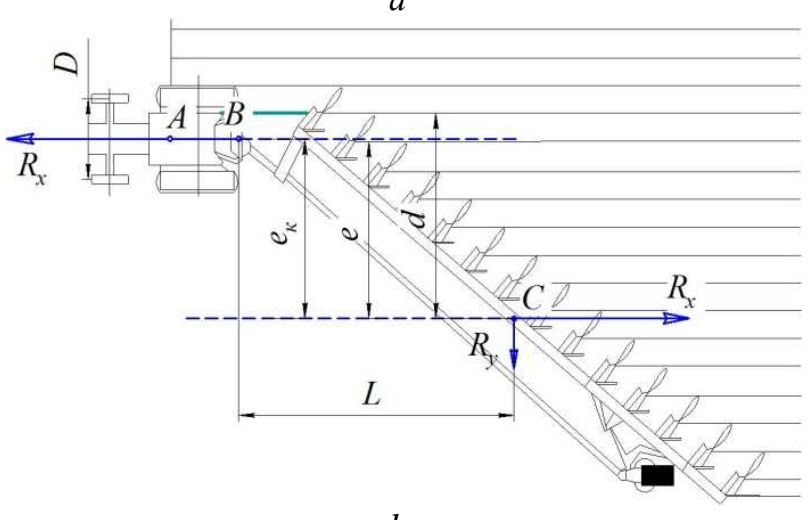

$b$

Fig. 4. To the calculation of plow adjustment in the horizontal plane: a) for plows with the number of bodies from 1 to $6 ; b$ ) for multi-body plows. A is the center of mass of the tractor; In - tractor traction point; $\mathrm{C}$ is the center of resistance of the plow; $\mathrm{D}$ is the track of the tractor;eis the optimal bias; $e_{\kappa}-$ structural displacement; $d$ is the distance from point $\mathrm{C}$ to the furrow wall; $\mathrm{P}_{x}$ - tractor traction force; $\mathrm{R}_{x}$ is the resistance force of the plow; $\mathrm{R}_{y}$ is the lateral component of the resistance force of the plow; L - shoulder side component of the resistance force of the plow

The inclination angle $\varepsilon_{i}$ of the tractor traction force is determined by the dependence

$$
\varepsilon_{i}=\operatorname{arctg} h_{i} / L_{i}
$$

where $\varepsilon_{i}$ is the angle of inclination of the tractor traction force $c i$ - body plow, deg.; $h_{i}$ is the height of the thrust point of the $i$-body plow, $\mathrm{m} ; L_{i}$ is the distance from the resistance point of the $i$-th body plow to the tractor traction point, $\mathrm{m}$.
To obtain specific data on the effect of friction forces on the lateral component, we will analyze the interaction of forces acting on the plow in the horizontal plane (Figure 4).

Traction force $\boldsymbol{P}_{\boldsymbol{x}}$ of the tractor overcomes the resistance of the plow $\boldsymbol{R}_{\boldsymbol{x}}$ to undercut the formation, crumbling and rotation of the formation and friction forces from the pressure of the field boards on the wall $f \boldsymbol{R}_{\boldsymbol{y}}$ and the bottom fmg of the furrow. Lateral component $\boldsymbol{R}_{y}$ of the resistance force of the plow $\boldsymbol{R}_{x y}$. presses against the furrow wall with field boards, as a result an additional friction force $f \boldsymbol{R}_{\boldsymbol{y}}$ appears.

It should be especially noted that the numerical value of this friction force $f \boldsymbol{R}_{\boldsymbol{y}}$ also depends on the magnitude of the displacement of the tractor thrust pointebetween the lines of the tractor thrust force $\boldsymbol{P}_{x}$ and the size $L$ of the lateral shoulder shoulder $\boldsymbol{R}_{\boldsymbol{y}}$ of the component of the plow drag force. If the tractor thrust force line $\boldsymbol{P}_{\boldsymbol{x}}$ is offset from the plow resistance line $\boldsymbol{R}_{\boldsymbol{x}}$ from the open furrow wall, then the pressure on the furrow wall will increase. If the tractor thrust force line $\boldsymbol{P}_{\boldsymbol{x}}$ is offset from the plow drag line $\boldsymbol{R}_{\boldsymbol{x}}$ to the open furrow wall, then the pressure on the furrow wall will decrease. Consequently, the friction force of the field boards against the furrow wall will also decrease.

The plow friction force during plowing is the sum of the friction from the plow gravity force fmg to the bottom of the furrow and the pressure on the furrow wall of the lateral resistance component $f \boldsymbol{P}_{i y}$.

Calculation of the friction forces of the plow from the pressure on the furrow wall of the lateral resistance component $\boldsymbol{P}_{i y}$

$$
f \boldsymbol{P}_{i y}=f \boldsymbol{R}_{i y}=0,5 \cdot(1 / 3) \cdot \boldsymbol{R}_{x}=0,5 \cdot(1 / 3) K \text { a i } b,
$$

where $f$ is the coefficient of friction of the field board on the soil, we take $0.5 ; \boldsymbol{P}_{i y}$ is the tractor traction force to overcome the friction forces of the plow from the pressure on the furrow wall of the lateral component of plow rotation, N; $\boldsymbol{R}_{i y}$ is the pressure force on the furrow wall of the lateral component of the plow rotation, $\mathrm{N} ; \boldsymbol{R}_{\boldsymbol{x}}$ is the plow coaxing force, $\mathrm{N} ; \mathrm{K}$ is the specific soil rotation during plowing; we accept $4.0 \mathrm{~N} / \mathrm{cm}^{2}=40,000$ $\mathrm{N} / \mathrm{m}^{2}$ for loamy soils; $a$ is the depth of plowing, we take $0.25 \mathrm{~m} ; i \cdot b$ is the width of the plow, taken equal to the 
number $i$ of buildings multiplied by the width of the capture of one body, $\mathrm{b}=0.55 \mathrm{~m}$.

The displacemente, obtained from the equation of moments of the pair of forces $\boldsymbol{P}_{\boldsymbol{x}}$ and $\boldsymbol{R}_{\boldsymbol{x}}$, is conventionally called optimal. The magnitude of the optimal displacement $e$ is determined from the equation of the moments of the pair of forces: the pull force $\mathbf{P}_{\boldsymbol{x}}$ of the tractor and the drag force $\mathbf{R}_{\boldsymbol{x}}$ of the plow

$$
M_{P R}=\boldsymbol{P}_{x} e=\boldsymbol{R}_{x} e=\boldsymbol{R}_{Y} L,
$$

where $\boldsymbol{M}_{\boldsymbol{P R}}$ is the moment of a pair of forces: tractor traction and plow resistance, $\mathrm{Nm} ; \boldsymbol{P}_{x} e$ is the moment of tractor traction, Nm; $\boldsymbol{P}_{x}-$ tractor traction force, $\mathrm{N} ; e_{-}$ shoulder (displacement) of tractor traction and plow resistance, $\mathrm{m} ; \boldsymbol{R}_{x} e-$ is the moment of resistance of the plow, Nm; $\boldsymbol{R}_{\boldsymbol{x}}$ is the longitudinal component of the resistance force of the plow, $\mathrm{N} ; \boldsymbol{R}_{\boldsymbol{y}}$ Lis the moment of the lateral component of the resistance force of the plow, $\mathrm{Nm} ; \boldsymbol{R}_{\boldsymbol{y}}$ is the lateral component of the resistance force of the plow, $\mathrm{N}$; Lis the shoulder of the lateral component of the resistance force of the plow, $\mathrm{m}$.

The shoulder (displacement) of the tractor traction force and the plow resistance obtained from the equation of moments of the pair of forces is written

$$
e=\boldsymbol{R}_{\boldsymbol{y}} L / \boldsymbol{R}_{\boldsymbol{x}},
$$

lateral component of the resistance force of the plow, on average, take $\boldsymbol{R}_{\boldsymbol{y}}=(1 / 3) \boldsymbol{R}_{\boldsymbol{x}}$, then the displacement

$$
e=(1 / 3) L \text {. }
$$

Shoulder L Lateral Component of Plow Resistance Force $\boldsymbol{R}_{\boldsymbol{y}}$

$$
L=\left[l_{1 x} \cdot(i-1)\right] / 2+\Delta,
$$

where $L$ is the shoulder of the lateral component of the resistance force $\boldsymbol{R}_{\boldsymbol{y}}$ of the plow, $\mathrm{m} ; l_{l x}$ is the distance between the toes of the cases, $\mathrm{m} ; i$ is the number of bodies, $\Delta$ is the distance from the 1 st body to the tractor traction point, $\mathrm{m}$.

For plowshares:

- Russian production- $l_{1}=(700 \ldots 800 \mathrm{~mm}=$ $(2 b \ldots 2,28 b)$ with a working width of the body $b=350 \mathrm{~mm} ; \Delta=1,0 \mathrm{~m}$;

- production in Europe- $l_{1 x}=(1,00 \ldots 1,20 \mathrm{mwith} b=$ $(0,30 \ldots 0,55 \mathrm{~m}) \Delta=1,2 \mathrm{~m}$.

The offset $e_{\kappa}$ of the point $\mathrm{B}$ of the tractor thrust from point $\mathrm{C}$ of the center of resistance of the plow, obtained by the graphoanalytical method taking into account the real dimensions of the track $\mathrm{D}$ of the tractor, is called constructive.

The magnitude of the structural displacement $e_{K}$ (Figure 5) depends on the distance $\mathrm{d}$ of the point $\mathrm{C}$ of the center of resistance of the plow to the furrow wall and the track D of the tractor:

$$
e_{K}=d-D / 2=i b / 2-D / 2=(i b-D) / 2 \text {, }
$$

where $e_{K}$ is the value of the structural displacement of the tractor traction point $\mathrm{B}$ from point $\mathrm{C}$ of the center of the plow resistance, $d$ is the distance from point $\mathrm{C}$ of the plow resistance center to the furrow wall, $i$ is the number of bodies, $b$ is the width of the body, $D$ is the tractor track.

Structural displacement of the tractor traction point, taking into account the width of the wheel:

$$
e_{K i}=d_{i^{-}}(D-W) / 2 \text {, }
$$

where $e_{K}$ is the magnitude of the structural displacement of the tractor traction point $\mathrm{B}$ from point $\mathrm{C}$ of the center of resistance of the plow, $\mathrm{m} ; d_{i}$ is the distance from the point $C_{i}$ of the center of resistance of the plow to the furrow wall, D is the tractor track, $\mathrm{m}$; $W$-wheel width, $m$.

The distance $d$ from the point of the center of resistance of the plow to the wall of the furrow is determined:

$$
d=i b / 2 \text {, }
$$

where $d$ is the distance from the point $\mathrm{C}$ of the center of resistance of the plow to the furrow wall, $i$ is the number of buildings, $b$ is the width of the housing.

Tractor design track with optimal shift of tractor traction point $\mathrm{B}$ :

$$
D=i \cdot b-2 e,
$$

where $D$ is the track of the tractor, m; $i$ - the number of buildings, $\mathrm{b}-$ the width of the housing, $\mathrm{m}$; $e$ is the value of the optimum displacement of the point $\mathrm{B}$ of the tractor link from point $\mathrm{C}$ of the center of resistance of the plow, $\mathrm{m}$.

The calculation results for determining the angle of inclination $\varepsilon$ of the tractor traction force, which depends on the height $h_{i}$ of the plow traction point, are shown in table 1 .

Table 1. The calculated values of the angle of inclination $\varepsilon$ of the tractor traction force in degrees and percent of the optimal value for various plows with a different number of bodies.

\begin{tabular}{|c|c|c|}
\hline $\begin{array}{c}\text { The number of } \\
i-\mathrm{b}\end{array}$ & $\begin{array}{c}\text { Tractor } \\
\text { traction angle } \\
\varepsilon_{\kappa},\end{array}$ & $\begin{array}{c}\text { The angle of inclination } \\
\varepsilon_{\kappa}, \% \text { of the optimal angle } \varepsilon \\
=26^{\circ} 30^{\prime}\end{array}$ \\
\hline 5 & 13 & 43.3 \\
\hline 9 & 8.5 & 28.3 \\
\hline 13 & 5.7 & 19 \\
\hline 17 & 3.9 & 13 \\
\hline 21 & 3.1 & 10.3 \\
\hline 25 & 3 & 10 \\
\hline 29 & 2.8 & 9,3 \\
\hline
\end{tabular}

The calculation results confirm the possibility of $100 \%$ balancing of the plow gravity with the number of bodies $1 \ldots 4$ of the vertical $\boldsymbol{P}_{z}$ component of the tractor pull force $\boldsymbol{P}_{x z}$ but exclude this possibility for multi-body plows, since the linkage mechanisms of tractors and plows do not allow to obtain the calculated values of the optimal point height traction.

Based on these results, the graphs were constructed, which are shown in Figure 4, from which it follows that with an increase in the number of bodies, the value of the angle of inclination of the traction force decreases curvilinearly.

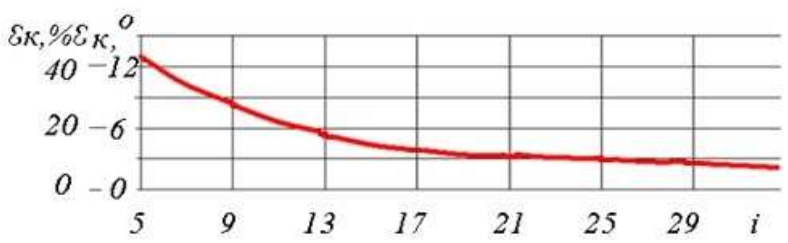

Fig. 5. Dependence of the angle $\varepsilon_{\kappa},{ }^{0}\left(\varepsilon_{\kappa}, \%\right.$ of the optimal value of the angle $\varepsilon=26^{\circ} 30^{\prime}$ ) of the slope of the tractor traction force on the number i of multi-body plow bodies. 
According to the calculations and the constructed schedule, it follows that the angle at the 5-body plow $\varepsilon_{5}=13^{\circ}$ is about $46 \%$ of the optimal $26^{\circ} 30^{\prime}$ value; the angle at the 9-body plow $\varepsilon_{9}=8^{\circ}$ is about $28 \%$ of the optimal value, the angle at the 13 -body plow $\varepsilon_{13}=6^{\circ}$ is about $20 \%$ of the optimal value, etc.

The design of the linkage mechanism of the plow and the linkage mechanism of the tractor do not always fully ensure the optimal value of the angle of direction of the draft line.

An optimal $100 \%$ balancing by the tractor traction force of the plow's gravity with the number of bodies 5 or more is not possible. Therefore, it is necessary to achieve the maximum anglesof the inclination of the tractor's longitudinal thrust to the horizon.

The calculated values of the friction force $\boldsymbol{F}_{f r G}$ of multi-body plows from the pressure on the bottom of the furrow by the force of gravity $\boldsymbol{P}_{i G}$ and the friction force $\boldsymbol{F}_{f r Y}$ from the pressure on the furrow wall of the lateral resistance component $\boldsymbol{P}_{i Y}$ are summarized in Table 2.

Table 2. The calculated values of the friction forces of multibody plows from the pressure on the bottom by the force of gravity $\boldsymbol{P}_{i G}$ and from the pressure on the furrow wall of the lateral resistance component $\boldsymbol{P}_{\boldsymbol{i Y}}$.

\begin{tabular}{|c|c|c|c|c|c|c|}
\hline $\begin{array}{c}\text { The number } I \\
\text { of } b .\end{array}$ & 6 & 8 & 10 & 12 & 14 & 20 \\
\hline Weight $\mathrm{G}, \mathrm{kg}$ & 2730 & 3200 & 4000 & 4800 & 5600 & 8000 \\
\hline $\begin{array}{l}\text { Friction } \\
\text { force } \boldsymbol{F}_{f r G} \\
=f \boldsymbol{P}_{i \boldsymbol{G}}, \mathrm{N}\end{array}$ & 1365 & 1600 & 2000 & 2400 & 2800 & 4000 \\
\hline $\begin{array}{l}\text { Friction } \\
\text { force } \boldsymbol{F}_{f r \boldsymbol{Y}} \\
=f \boldsymbol{P}_{\boldsymbol{i} y}, \mathrm{~N}\end{array}$ & 5497 & 7330 & 9163 & 10995 & 12828 & 18326 \\
\hline$f\left(\boldsymbol{P}_{i \boldsymbol{G}}+\boldsymbol{P}_{i \boldsymbol{Y}}\right), \mathrm{N}$ & 6862 & 8930 & 11163 & 13395 & 15628 & 22326 \\
\hline $\begin{array}{r}\% \text { of } \boldsymbol{R}_{\boldsymbol{x}} \text { at } \\
\mathrm{b}=300 \mathrm{~mm}\end{array}$ & 38 & 37 & 37 & 37 & 37 & 37 \\
\hline $\begin{array}{c}\% \text { of } \boldsymbol{R}_{x} \text { at } \\
\mathrm{b}=550 \mathrm{~mm}\end{array}$ & 20 & 20 & 20 & 20 & 20 & 20 \\
\hline
\end{tabular}

From the analysis of the data obtained, the percentage of the total frictional forces to the traction resistance of the plow shows that the efficiency of the plow is in the range $38 \ldots 20 \%$ of $\boldsymbol{R}_{x}$ or from 0.62 to 0.8 .

Thus, the optimal height $h_{i}$ of the point of the thrust of the plow is one that provides the angle $\varepsilon$ of inclination of the thrust force $\boldsymbol{P}_{x z}$ of the tractor, equal to the angle $\varphi$ of friction of the plow on the soil.

Also, calculations were made of the values of the structural displacement $e_{K I}$ of the distance $d_{i}$ from the point of the center of resistance of the plow to the furrow wall, the calculated track of the tractor depending on the number $I$ of plow bodies with different working widths of one body, the calculation results are shown in table 3 .

Based on the results of the obtained data, graphical dependences were constructed showing the dependence of the optimal displacement e of the tractor traction line and distance $\mathrm{d}$ from the point of the center of resistance of the plow to the furrow wall on the number of bodies $i$ (Fig. 6).
Table 3. Numerical values of the shoulders L, displacements: $e$ and $e_{K}$, the estimated $\mathrm{D}$ track of the tractor depending on the number $i$ of plow bodies with a working width of one body: $\mathrm{b}=$ $0.3 \mathrm{~m} / \mathrm{b}=0.55 \mathrm{~m}$

\begin{tabular}{|l|c|c|c|c|c|c|}
\hline The number i of b. & 2 & 6 & 10 & 14 & 20 & 30 \\
\hline Working width, m & $0.6 /$ & $1.8 /$ & $3.0 /$ & $4.2 /$ & $6.0 /$ & $9.0 /$ \\
& 1.1 & 3.3 & 5.5 & 7.7 & 11.0 & 16.5 \\
\hline Shoulder L Strength & $1.5 /$ & $3.5 /$ & $5.5 /$ & $7.5 /$ & $10.5 /$ & $15.5 /$ \\
$\mathrm{R}_{\mathrm{Y}}, \mathrm{m}$ & 1.8 & 4.0 & 6.6 & 9.0 & 12.6 & 18.6 \\
\hline Offset e, m optim. & $0.45 /$ & $1.16 /$ & $1.8 /$ & $2.5 /$ & $3.5 /$ & $5.1 /$ \\
& 0.54 & 1.33 & 2.2 & 3.0 & 4.2 & 6.2 \\
\hline eK, m construct. & -0.325 & 0.275 & 0.975 & 1.575 & 4.825 & 7.575 \\
\hline \% of e calc & & & 44.3 & 52.5 & 114.8 & 122.0 \\
\hline $\begin{array}{l}\text { Track D, m } \\
\text { calculated ate, m } \\
\text { optim. }\end{array}$ & $-0.3 /$ & $-0.52 /$ & $-0.6 /$ & $-0.8 /$ & $-1.0 /$ & $-1.2 /$ \\
Distance di, m & 0.02 & 0.64 & 1.1 & 1.7 & 2.6 & 4.1 \\
\hline
\end{tabular}

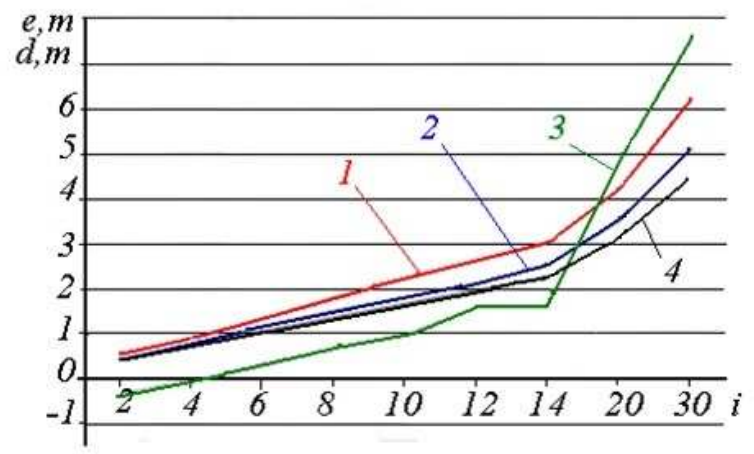

Fig. 6. The dependence of the optimal displacement $e$ of the tractor traction line and the distance $d$ from the point of the center of resistance of the plow to the furrow wall on the number of bodies $i$ : 1 - with a body width of $0.55 \mathrm{~m} 2$ - with a working width of $0.30 \mathrm{~m} ; 3$ - structural displacement $e_{K} ; 4$ the distance from the center of resistance of the plow to the wall of the furrow.

An analysis of Table 3 and the graphs of Figure 6 shows that for plows with a small number of bodies it is almost impossible to combine the tractor thrust point with the optimal shift of the plow thrust point.

Track tractors in class $0.6 \mathrm{tf} ; 0.9 \mathrm{tf} ; 1.4 \mathrm{tf} ; 3 \mathrm{tf} ; 5 \mathrm{tf}$ is in the range from 1200 to $2744 \mathrm{~mm}$, for example, at the tractor Standard equipment K-744 gauge D $=2100 \mathrm{~mm}$ and Premium equipment K-744 gauge D $=2115 \mathrm{~mm}$, wheel width $\mathrm{W}=750 \mathrm{~mm}$.

The value of the optimum displacement $e$ for smallbody plows with a working width of less than $2.0 \mathrm{~m}$ does not agree with the track of the tractor. Therefore, the thrust point of the plow is forced to be estimated towards the point of tractor pull. As a result, the pressure on the furrow wall will increase, and the friction force will increase accordingly.

For plows with a working width of more than $2.0 \mathrm{~m}$, the lateral pressure of the plow on the walls of the furrows is not completely balanced (up to $80 \%$ ).

For plows with a working width of $6 \mathrm{~m}$ or more, the traction points of the plow and tractor coincide, which allows you to completely (100\%) balance the lateral pressure of the plow on the walls of the furrows.

With a working width of $0.3 \mathrm{~m}$ for all plows, the bridge construction of the chassis of the tractors does not 
allow $100 \%$ to completely balance the lateral pressure of the plow on the furrow walls.

With a working width of $0.5 \mathrm{~m}$ for plows with a number of hulls of 12 or more, the design of the axles of the chassis of the tractors makes it possible to completely balance the lateral pressure of the plow on the furrow walls by $100 \%$.

Thus, the optimum $\varepsilon$ displacement of the point $\mathrm{P}$ of the thrust of the plow ensures full balancing of the lateral moment $\boldsymbol{R} \boldsymbol{y}$ of the component of the resistance force of the plow $\boldsymbol{R} \boldsymbol{x}$ relative to the point B of the thrust of the plow, reduces the friction force on the furrow walls to zero and increases the efficiency of the plow to 1.00 .

To solve the problems of optimizing the plow setting, an individual approach to each group of plows is needed: I - I with the number of bodies (from 2 to 5); II with the number of buildings (from 6 to 12); III - I with the number of buildings ( 13 or more).

Take into account that the track gauge of the tractors for the I and II groups of plows does not allow to combine the thrust points of the tractor and the plow, which leads to a decrease in the efficiency of the plow. In the longitudinal-vertical plane, attach the tractor to the plow so that the points: A, B, C - are on one straight line.

Further, so that the pole $\pi$ is at point $\mathrm{A}$ and the point $\mathrm{B}$ - of the plow thrust coincides in height with the point $\mathrm{B}$ - of the tractor thrust. In the horizontal plane, in order to reduce the pressure of field planks on the furrow wall, it is necessary: to move the toe of the ploughshare of the first plow body from the furrow wall to a predetermined working width; move the thrust point $\mathrm{B}$ of the plow from the furrow wall by the difference in values $\left(d_{i^{-}}\right.$ $e_{K}$ ); combine the thrust point $\mathrm{B}$ of the plow with the thrust point $\mathrm{B}$ of the tractor; the wheels (track) of the tractor must be in the furrow.

\section{Conclusions}

The optimization of the adjustment of the plow, carried out in two planes, allows reducing pressure forces of the plow on the bottom and walls of the furrows and increase its efficiency.

1. In the longitudinal-vertical plane, the optimal height $h_{i}$ of the point of the thrust of the plow is one that provides the angle $\varepsilon_{i}$ of the slope of the thrust force $P_{x z}$ of the tractor equal to the angle $\varphi$ of friction of the plow on the soil.

2. In the horizontal plane, the optimum point of displacement $\varepsilon$ of the point $\mathrm{B}$ of the thrust of the plow is one that increases the efficiency of the plow to 1.00 .

3. Depending on the number of bodies, the plow manufacturer of plows should provide for the possibility of locating the plow traction point:

- in height, so that the angle of inclination of the draft line is equal to the angle of friction of the body material on the soil;

- in width - the possibility of shifting the traction point from the line of the center of resistance point towards the furrow by an optimal valueeequal to $1 / 3$ of the length from the center of resistance to the traction point.

4. To manufacturers of tractors for aggregation with plowshares:

- the position of the tractor traction point: in height should coincide with the traction point of the plow;

- the point $\pi$ of the intersection of the lines of the longitudinal linkage linkage should coincide with the center of mass of the tractor;

- the tractor track should be equal to twice the size from the middle of the furrow to the point of traction of the plow;

- the width of the wheels (tracks) should be no more than the width of the furrow.

\section{References}

1. A. Valiev, I. Mukhametshin, F. Muhamadyarov et al., Theoretical substantiation of parameters of rotary subsoil loosener, Engineer. for Rural Developm., 18, 312-318 (2019)

2. A.R. Valiev, F.F. Muhamadyarov, B.G. Ziganshin, Substantiation of constructive and technological parameters of a new disc harrow, Russ. Agricult. Sci., 43(2), 194 (2017)

3. F.F. Yarullin, R.I. Ibyatov, S.M. Yakhin, R.K. Gainutdinov, Results of field studies of a tillage implement with ellipsoid disks, Bull. of Kazan State Agrar. Univer., 14(2), 123-127 (2019)

4. C.M. Yakhin, I.I. Aliakberov, L.M. Nuriev, F.F. Yarullin, Kinematics of a needle ellipsoidal disk of a rotary tillage implement, Techn. and equipment for village, 2(272), 12-15 (2020)

5. I. Maksimov, N. Adigamov, A. Mustafin et al., Theoretical fundamentals for determining soil erosion potential (energy concept). Part 1. Periodic. Quimica, 16(31), 540-557 (2019)

6. I. Galiev, C. Khafizov, N. Adigamov, R. Khusainov, Increase of efficiency of tractors use in agricultural production, Engineer. for Rural Developm., 17, 373-377 (2018)

7. C. Khafizov, A. Nurmiev, R. Khafizov, N. Adigamov, Method of justification for parameters of tractor-implement unit with regards to their impact on crop productivity, Engineer. for Rural Developm., 17, 176-185 (2018)

8. R. Khafizov, C. Khafizov, A. Nurmiev, I. Galiev, Optimization of main parameters of tractor and unit for seeding cereal crops with regards to their impact on crop productivity, Engineer. for Rural Developm., 17, 168-175 (2018)

9. A. Nurmiev, C. Khafizov, R. Khafizov, B. Ziganshin, Optimization of main parameters of tractor working with soil-processing implement, Engineer. for Rural Developm., 17, 161-167 (2018)

10. V.M. Khalansky, I.V. Gorbachev, Agricultural machinery (Moscow, 2003) 
11. Website of LEMKEN GmbH \& Co. KG, Retrieved from: https://lemken.com/en/soilcultivation/ploughing/mounted-ploughs/europal/
12. G.E. Listopad, G.K. Demidov, B.D. Zonov et al., Agricultural and reclamation machines (Moscow, 1986) 